Article

\title{
In Vivo Positive Magnetic Resonance Imaging of Brain Cancer (U87MG) Using Folic Acid-Conjugated Polyacrylic Acid-Coated Ultrasmall Manganese Oxide Nanoparticles
}

\author{
Shanti Marasini ${ }^{1}$, Huan Yue ${ }^{1}$, Son-Long Ho ${ }^{1} \oplus$, Ji-Ae Park ${ }^{2} \oplus$, Soyeon Kim ${ }^{2}$, Ji-Ung Yang ${ }^{2}$, Hyunsil Cha ${ }^{3}$, \\ Shuwen Liu ${ }^{1}$, Tirusew Tegafaw ${ }^{1}{ }^{\circledR}$, Mohammad Yaseen Ahmad ${ }^{1}{ }^{\circledR}$, Abdullah Khamis Ali Al Saidi ${ }^{1}$, Dejun Zhao ${ }^{1}$, \\ Ying Liu ${ }^{1}$, Kwon-Seok Chae ${ }^{4}$, Yongmin Chang ${ }^{3, *}$ and Gang-Ho Lee ${ }^{1, *}$ (D) \\ 1 Department of Chemistry, College of Natural Sciences, Kyungpook National University, Taegu 41566, Korea; \\ shantimarasini.sm@gmail.com (S.M.); 20100819@hanmail.net (H.Y.); sonlongh@gmail.com (S.-L.H.); \\ liushuwen0701@gmail.com (S.L.); tegafawtirusew@yahoo.com (T.T.); yaseen.knu@gmail.com (M.Y.A.); \\ Abdullah_al_saidi@hotmail.com (A.K.A.A.S.); djzhao.chem@gmail.com (D.Z.); \\ perseverance_ly@outlook.com (Y.L.) \\ 2 Division of Applied RI, Korea Institute of Radiological and Medical Sciences (KIRAMS), Seoul 01812, Korea; \\ jpark@kirams.re.kr (J.-A.P.); ksy0188@kirams.re.kr (S.K.); wjy11300@kirams.re.kr (J.-U.Y.) \\ 3 Department of Molecular Medicine, School of Medicine, Kyungpook National University, Taegu 41944, Korea; \\ hscha1002@daum.net \\ 4 Department of Biology Education, Teachers' College, Kyungpook National University, Taegu 41566, Korea; \\ kschae@knu.ac.kr \\ * Correspondence: ychang@knu.ac.kr (Y.C.); ghlee@mail.knu.ac.kr (G.-H.L.)
}

Citation: Marasini, S.; Yue, H.; Ho, S.-L.; Park, J.-A.; Kim, S.; Yang, J.-U.; Cha, H.; Liu, S.; Tegafaw, T.; Ahmad, M.Y.; et al. In Vivo Positive Magnetic Resonance Imaging of Brain Cancer (U87MG) Using Folic

Acid-Conjugated Polyacrylic Acid-Coated Ultrasmall Manganese Oxide Nanoparticles. Appl. Sci. 2021, 11, 2596. https://doi.org/10.3390/ app11062596

Academic Editor: Marwan Al-Haik

Received: 31 January 2021

Accepted: 9 March 2021

Published: 15 March 2021

Publisher's Note: MDPI stays neutral with regard to jurisdictional claims in published maps and institutional affiliations.

Copyright: (c) 2021 by the authors. Licensee MDPI, Basel, Switzerland. This article is an open access article distributed under the terms and conditions of the Creative Commons Attribution (CC BY) license (https:// creativecommons.org/licenses/by/ $4.0 /)$.
Featured Application: Cancer-targeting $T_{1}$ magnetic resonance imaging contrast agent.

Abstract: Ultrasmall nanoparticles are potential candidates for application as high-performance imaging agents. Herein, we present the synthesis and characterization of folic acid (FA)-conjugated polyacrylic acid (PAA)-coated $\mathrm{MnO}$ nanoparticles with an average particle diameter of $2.7 \mathrm{~nm}$. FA conferred cancer-targeting ability, while PAA conferred good colloidal stability and low cellular cytotoxicity on the FA-PAA-coated MnO nanoparticles. Further, the nanoparticles exhibited a high relaxivity $\left(\mathrm{r}_{1}\right)$ value of $9.3 \mathrm{~s}^{-1} \mathrm{mM}^{-1}\left(\mathrm{r}_{2} / \mathrm{r}_{1}=2.2\right)$. Their application potential as cancer-targeting $\mathrm{T}_{1}$ magnetic resonance imaging contrast agents was confirmed by their enhanced $\mathrm{T}_{1}$ contrast enhancements at the brain cancer (U87MG) site upon intravenous administration to mice tails.

Keywords: brain cancer; cancer targeting; folic acid; magnetic resonance imaging; ultrasmall manganese oxide nanoparticles

\section{Introduction}

Cancer is a deadly disease with high recurrence and mortality rates [1]. An accurate cancer diagnosis at the early stages is vital for the patient's timely treatment. Magnetic resonance imaging (MRI) is the clinically relevant and common method for preoperatively estimating the prognosis of a cancer patient [2,3]. Contrast agents are generally used in MRI [4,5], most commonly Gd-chelates [6-8], to further improve the cancer diagnosis. Recently, nanoparticles have attracted increasing research attention owing to their better contrasting abilities than those of commercial molecular agents $[5,9,10]$.

Among nanoparticles, ultrasmall manganese oxide $(\mathrm{MnO})$ nanoparticles are receiving special research interest due to their potential applicability as contrast agents in positive $\left(\mathrm{T}_{1}\right)$ MRI [11,12]. Although bulk $\mathrm{MnO}$ is antiferromagnetic, $\mathrm{MnO}$ nanoparticles exhibit considerable magnetization at room temperature, attributable to the unpaired $3 \mathrm{~d}$-electron spins of $\mathrm{Mn}^{2+}$ on the nanoparticle surfaces $[13,14]$. Notably, the high pure spin magnetic moment $(S=5 / 2)$ of $\mathrm{Mn}^{2+}$ can strongly induce longitudinal water proton spin relaxations 
since slow electron spin motions match well with proton spin relaxations [7,8]. In addition, $\mathrm{Mn}^{2+}$ is nearly non-toxic in limited dosages [12,15]. Thus, $\mathrm{MnCl}_{2}$ has been approved for use in animals as a $\mathrm{T}_{1}$ MRI contrast agent by the United States Food and Drug Administration $[12,15]$.

Ultrasmall nanoparticle contrast agents possess an additional advantage over molecular agents since cancer-targeting ligands and drugs can easily attach to the nanoparticle surfaces. Moreover, the conjugation of cancer-targeting ligands to the nanoparticles further improves their contrasting abilities. Among cancer-targeting ligands, folic acid (FA) has been widely used owing to its high affinity towards folate receptors, which are overexpressed on diverse cancer cells [16-19]. Furthermore, FA can easily be conjugated to surface-modified nanoparticles through an amide bond [20-23].

Small molecules such as FA are less efficient in providing good colloidal stability to nanoparticles compared to polymers. This is owing to many hydrophilic and binding groups of polymers that can attach to the nanoparticles [24,25]. Polyacrylic acid (PAA) with numerous $\mathrm{COOH}$ groups (i.e., one $\mathrm{COOH}$ group per monomer unit) belongs to such polymers [26-28]. Therefore, herein, FA was conjugated with PAA, and subsequently the obtained FA-PAA ligands were grafted onto the nanoparticle surfaces.

Herein, we report the synthesis and extensive characterization of FA-PAA-coated $\mathrm{MnO}$ nanoparticles. We measured in vitro cellular cytotoxicities of these nanoparticles and investigated their relaxometric properties and effectiveness as cancer-targeting $\mathrm{T}_{1} \mathrm{MRI}$ contrast agents using brain cancer model nude mice.

\section{Materials and Methods}

\subsection{Materials}

$\mathrm{MnCl}_{2} \cdot 4 \mathrm{H}_{2} \mathrm{O}(>99 \%), \mathrm{NaOH}(>99 \%), \mathrm{FA}(>97 \%)$, PAA $\left(\mathrm{M}_{\mathrm{W}}=\sim 1800 \mathrm{amu}\right)$, dimethyl sulfoxide (DMSO) (99.9\%), triethylene glycol (TEG) $(99 \%), \mathrm{N}, \mathrm{N}^{\prime}$-dicyclohexylcarbodiimide (DCC) (99\%), 4-(dimethylamino) pyridine (DMAP) (>99\%), tert-butyl N-(2-aminoethyl) carbamate (EDA-Boc) (>98\%), triethylamine (TEA) (>99\%), trifluoroacetic acid (TFA) (99\%), Roswell Park Memorial Institute (RPMI)-1640, and Dulbecco's Modified Eagle Medium (DMEM) were purchased from Sigma-Aldrich, USA. Ethyl acetate (99.9\%), chloroform (99.9\%), and ethanol (99.99\%) were purchased from Duksan Chemical Co., South Korea. All chemicals were used without any further purification.

\subsection{Preparation of FA-PAA}

FA-PAA was prepared via three steps, i.e., FA-EDA-Boc $\rightarrow$ FA-EDA-TFA $\rightarrow$ FA-PAA (Figure 1). To prepare FA-EDA-Boc (the first step in Figure 1), $0.9 \mathrm{mmol}$ of FA was dissolved in $15 \mathrm{~mL}$ of DMSO at $60{ }^{\circ} \mathrm{C}$ under an $\mathrm{N}_{2}$ flow and magnetic stirring in a $100-\mathrm{mL}$ threeneck round-bottom flask. After the solution temperature decreased to room temperature, $0.1 \mathrm{mmol}$ of DMAP and $1.0 \mathrm{mmol}$ of DCC were added to the solution using a syringe, followed by magnetic stirring for another $1 \mathrm{~h}$. Next, $1.8 \mathrm{mmol}$ of EDA-Boc was added to the solution with a syringe and the reaction proceeded for $12 \mathrm{~h}$. The obtained product solution was added slowly to cold ethyl acetate. The obtained yellow precipitate, i.e., FA-EDA-Boc, was washed with ethyl acetate several times. To prepare FA-PAA-TFA (the second step in Figure 1), 2 mL of TFA was added to the yellow precipitate obtained above in a $100-\mathrm{mL}$ three-neck round-bottom flask, and the solution was magnetically stirred for $3 \mathrm{~h}$ at room temperature until it dissolved in TFA. Next, chloroform was slowly added to the solution until a yellow precipitate was formed. The upper clear solution was removed, and the remaining precipitate was washed thrice with ethyl acetate. The obtained product, i.e., FA-EDA-TFA, was dried to powder form using a rotary evaporator. To prepare FAPAA (the third step in Figure 1), the above FA-EDA-TFA was added to $5 \mathrm{~mL}$ of DMSO in a $100-\mathrm{mL}$ three-neck round-bottom flask, followed by the addition of $40 \mu \mathrm{L}$ of TEA using a syringe. The mixture was magnetically stirred until a clear solution was obtained. Separately, $1.5 \mathrm{mmol}$ of PAA was added to $20 \mathrm{~mL}$ of DMSO under an $\mathrm{N}_{2}$ flow at $60{ }^{\circ} \mathrm{C}$ in a $100-\mathrm{mL}$ three-neck round-bottom flask, and the mixture was magnetically stirred until a 
clear solution was obtained. After the solution temperature decreased to room temperature, $1.5 \mathrm{mmol}$ of DCC and $0.15 \mathrm{mmol}$ of DMAP were added using a syringe, and the reaction continued for $1 \mathrm{~h}$. Thereafter, the above-prepared FA-EDA-TFA solution was slowly added to the PAA solution using a syringe. The reaction continued for $12 \mathrm{~h}$ with magnetic stirring. The obtained solution was dialyzed $(\mathrm{MWCO}=1000 \mathrm{amu}$ ) against triple-distilled water for $24 \mathrm{~h}$. After dialysis, the remaining solution inside the bag was filtered using a Whatman filter paper (Sigma-Aldrich, USA) and subsequently evaporated using a rotary evaporator to obtain a dark yellow solid product, i.e., FA-PAA.

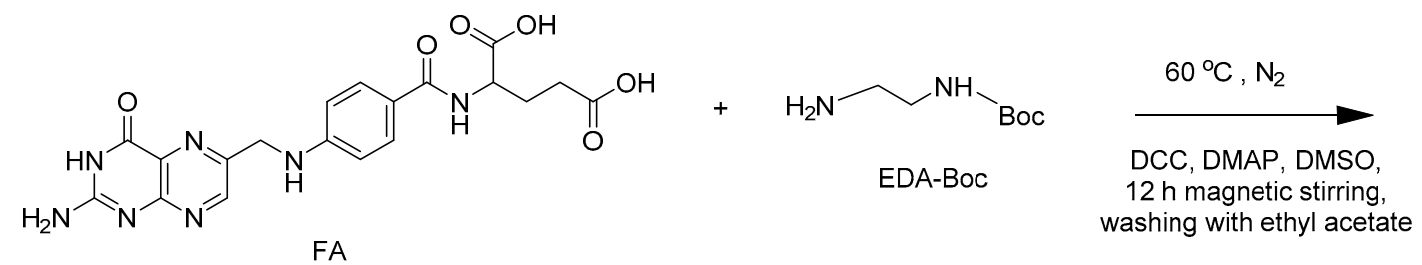<smiles>CCOC(=O)NCCNC(=O)C(CCC(=O)NCCNC(=O)OC(C)(C)C)NC(=O)c1ccc(NCc2cnc3nc(N)[nH]c(=O)c3n2)cc1</smiles>

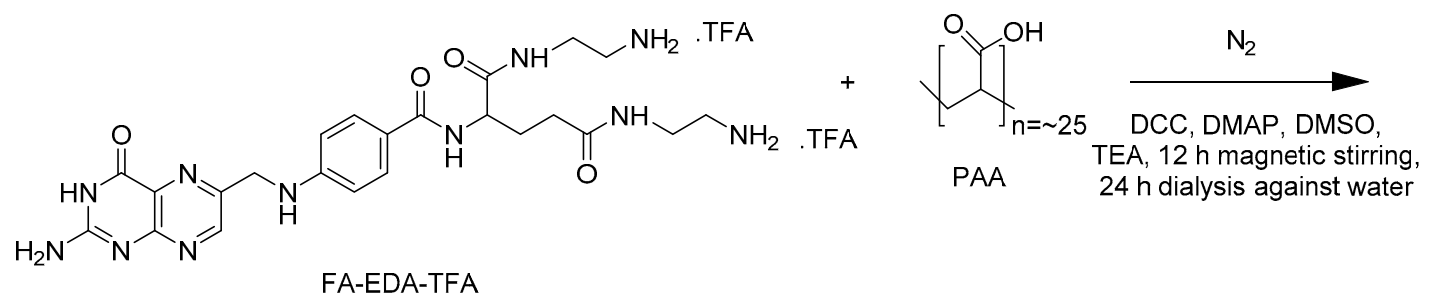<smiles>CC1C(CCCNC(=O)CCC(NC(=O)c2ccc(NCc3cnc4nc(N)[nH]c(=O)c4n3)cc2)C(=O)O)NC(=O)C1CCC(CC(C)(C)C)C(=O)O</smiles>

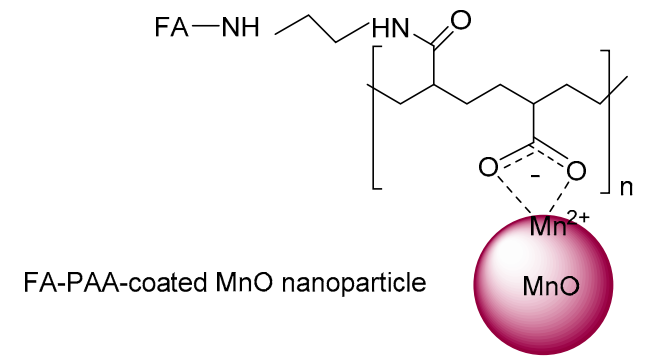

Figure 1. Synthesis of folic acid-polyacrylic acid (FA-PAA) via three steps and the FA-PAA-coated manganese oxide (MnO) nanoparticles via one-step.

\subsection{Preparation of FA-PAA-Coated $M n O$ Nanoparticles}

To prepare the FA-PAA-coated $\mathrm{MnO}$ nanoparticles through a simple one-pot polyol method (last step in Figure 1), $0.25 \mathrm{mmol}$ of FA-PAA and $2 \mathrm{mmol}$ of $\mathrm{MnCl}_{2} \cdot 4 \mathrm{H}_{2} \mathrm{O}$ were 
dissolved in $20 \mathrm{~mL}$ of TEG in a 100-mL three-neck round-bottom flask under an $\mathrm{N}_{2}$ flow and magnetic stirring at room temperature. In a separate beaker, $10 \mathrm{mmol}$ of $\mathrm{NaOH}$ was dissolved in $15 \mathrm{~mL}$ of TEG at room temperature: The $\mathrm{NaOH}$ solution was slowly added to the above solution with a syringe until the $\mathrm{pH}$ reached $\sim 10$. Then, the reaction temperature slowly increased from room temperature to $110{ }^{\circ} \mathrm{C}$ and maintained at that temperature for $15 \mathrm{~h}$. The solution was cooled to room temperature and transferred to a $500 \mathrm{~mL}$ beaker. The product solution was then washed with $400 \mathrm{~mL}$ of ethanol thrice to remove TEG, $\mathrm{Mn}^{2+}, \mathrm{Cl}^{-}, \mathrm{Na}^{+}, \mathrm{OH}^{-}$, and FA-PAA. To this end, the product solution was diluted with $400 \mathrm{~mL}$ of ethanol and then, kept in a refrigerator $\left(\sim 4^{\circ} \mathrm{C}\right)$ for a few days until the product nanoparticles were precipitated. The upper clear portion of the solution was removed, and the remaining product solution was washed with ethanol again. This washing process was repeated thrice. Ethanol was removed from the product nanoparticles by adding $400 \mathrm{~mL}$ of triple-distilled water to the product solution and then, concentrating it to a volume of 20-30 mL using a rotary evaporator. This washing process was repeated thrice. The product solution was split into two parts: One-half volume was freeze-dried to a powder sample under a vacuum, whereas the other half volume was used to make an aqueous nanoparticle suspension by diluting it with triple-distilled water.

\subsection{Characterizations}

A high-resolution transmission electron microscope (HRTEM) (Titan G2 Chemi STEM CS Probe, FEI, Hillsboro, Oregon, USA; $200 \mathrm{kV}$ accelerating voltages) was employed to measure the nanoparticle particle diameters. For the measurement, a minute amount of the nanoparticle suspension sample diluted with triple-distilled water was dropped onto an amorphous carbon film coated-copper grid (PELCO No.160, TED PELLA, Inc., Redding, CA, USA). The sample was dried in air at room temperature prior to the measurements. The hydrodynamic diameters of the nanoparticles were measured using a dynamic lightscattering (DLS) particle size analyzer (Zetasizer Nano ZS, Malvern, Malvern, UK) and a nanoparticle suspension sample diluted with triple-distilled water $(0.1 \mathrm{mM} \mathrm{Mn})$. The zeta potentials (Zetasizer Nano ZS, Malvern, Malvern, UK) were measured using a nanoparticle suspension sample diluted with triple-distilled water $(0.1 \mathrm{mM} \mathrm{Mn})$. The structural characterization of the nanoparticles was performed using an X-ray powder diffractometer (XRD) (X'PERT PRO MRD, Philips, The Netherlands) with unfiltered $\mathrm{CuK} \alpha$ radiation $(\lambda=1.54184 \AA)$ and powder samples. The Mn concentration in the aqueous nanoparticle suspension sample was determined via inductively coupled plasma-atomic emission spectroscopy (ICP-AES) (IRIS/AP, Thermo Jarrell Ash Co., Waltham, MA, USA). Fourier transform infrared (FT-IR) absorption spectroscopy (Galaxy 7020A, Mattson Instrument, Inc., Madison, WI, USA) was used to prove the nanoparticle surface coating. $\mathrm{KBr}$ pellets of the powder samples were used to record the FT-IR absorption spectra. Thermogravimetric analysis (TGA) (SDT-Q600, TA Instrument, New Castle, DE, USA) was used to estimate the surface-coating amount on the nanoparticles. The TGA curve of the powder sample was recorded between room temperature and $700{ }^{\circ} \mathrm{C}$ under an $\mathrm{N}_{2}$ flow. A vibrating sample magnetometer (VSM) (7407-S, Lake Shore Cryotronics Inc., Westerville, OH, USA) was employed to investigate the magnetic properties of the nanoparticles using the powder sample (approximately 15-20 mg). The magnetization (M) versus the applied field (H) (i.e., $\mathrm{M}-\mathrm{H})$ curves $(-2.0 \mathrm{~T} \leq \mathrm{H} \leq 2.0 \mathrm{~T})$ at $\mathrm{T}=100$ and $300 \mathrm{~K}$ were recorded. The net mass of the $\mathrm{MnO}$ nanoparticles extracted from the TGA curve was used to estimate the net $\mathrm{M}$ value of the sample (only $\mathrm{MnO}$ nanoparticles without FA-PAA).

\subsection{Relaxometric Property Measurements}

The original aqueous nanoparticle suspension sample was diluted with triple-distilled water to prepare aqueous nanoparticle suspension samples with various Mn-concentrations $(1.0,0.5,0.25,0.125$, and $0.0625 \mathrm{mM})$. The longitudinal $\left(\mathrm{T}_{1}\right)$ and transverse $\left(\mathrm{T}_{2}\right)$ water proton spin relaxation times were measured for these solutions using a 3.0 T MRI scanner (Magnetom Trio Tim, Siemens, Munchen, Bayern, Germany). An inversion recovery 
method was employed to obtain the $T_{1}$ relaxation times [29]. A multiple spin-echo method with a Carr-Purcell-Meiboom-Gill pulse sequence was employed to obtain the $\mathrm{T}_{2}$ relaxation times [29]. Thereafter, $1 / T_{1}$ and $1 / T_{2}$ were plotted as a function of Mn-concentration to estimate the longitudinal $\left(\mathrm{r}_{1}\right)$ and transverse $\left(\mathrm{r}_{2}\right)$ water proton spin relaxivities from the slopes, respectively.

\subsection{Cellular Toxicity Measurements}

A CellTiter-Glo Luminescent Cell Viability Assay (Promega, Madison, WI, USA) was employed to obtain the cellular toxicity of the aqueous nanoparticle suspension sample. A luminometer (Synergy HT, BioTek, Winooski, VT, USA) was used to quantify the intracellular adenosine triphosphate in this assay. Normal mouse hepatocyte (NCTC1469) and human prostate cancer (DU145) cell lines were employed for the tests. The cells were incubated for $24 \mathrm{~h}$ on a 24 -well cell culture plate $\left(5 \times 10^{4}\right.$ cell density, $500 \mu \mathrm{L}$ of cells per well, $5 \% \mathrm{CO}_{2}$, and a temperature of $37^{\circ} \mathrm{C}$ ). RPMI- 1640 and DMEM were employed as the culture media for the DU145 and NCTC1469 cells, respectively. The original concentrated nanoparticle suspension sample was diluted with a sterile phosphate-buffered saline (PBS) solution to make five test nanoparticle suspension samples, and $2 \mu \mathrm{L}$ of each test nanoparticle suspension sample was added to the above-cultured cells to obtain $\mathrm{Mn}$ concentrations of 10,50,100, and $200 \mu \mathrm{M}$ in the cells. Thereafter, the treated cells with nanoparticle suspension samples were incubated for $48 \mathrm{~h}$. A total of $200 \mu \mathrm{L}$ of CellTiter-Glo reagent was added to $200 \mu \mathrm{L}$ of the above incubated treated cells per well and the cells were lysed for $30 \mathrm{~min}$ on an orbital shaker. The viabilities of the cells were measured using the luminometer $(300-700 \mathrm{~nm})$, following which they were normalized with respect to those of the control cells with $0.0 \mathrm{M} \mathrm{Mn}$. The average cell viabilities were estimated from three measurements.

\subsection{Preparation of Cancer Model Nude Mice}

The human glioblastoma (U87MG) cancer cells were incubated for $24 \mathrm{~h}$ at $37^{\circ} \mathrm{C}$ in air containing $5 \% \mathrm{CO}_{2}$ using the culture medium made of RPMI- 1640 containing $1 \%(v / v)$ of penicillin-streptomycin and $10 \%(v / v)$ of fetal bovine serum. Two BALB/c nude mice (male, 5 weeks old, $\sim 20 \mathrm{~g}$ ) were inoculated to their brains with $5 \times 10^{6} \mathrm{U} 87 \mathrm{MG}$ cancer cells suspended in a $100 \mu \mathrm{L}$ of PBS solution. The MRI experiments were conducted 3 weeks after the cancer-cell inoculation.

\subsection{In Vivo $T_{1}$ MRI Experiments}

The same 3.0 T MRI scanner was employed to measure the in vivo $T_{1}$ MR images. The tails of the above-prepared cancer model nude mice were intravenously injected with the aqueous nanoparticle suspension sample (injection dose $=\sim 0.1 \mathrm{mmol} \mathrm{Mn} / \mathrm{kg}$ ). The mice were anesthetized with $1.5 \%$ isoflurane in oxygen. The imaging measurements were conducted prior and posterior to the injection of the sample. During the measurements, the body temperature of the mice was kept at $37^{\circ} \mathrm{C}$ using a warm water blanket. Following the measurements, the mice were revived from anesthesia and placed in a cage with free access to food and water. For measurements, radio-frequency spoiled $\mathrm{T}_{1}$-weighted gradientrecalled echo (GRE) sequences were used. The typical measurement parameters are as follows: Applied MR field $(\mathrm{H})=3 \mathrm{~T}$, temperature $=37^{\circ} \mathrm{C}$, echo time $=12 \mathrm{~ms}$, repetition time $=564 \mathrm{~ms}$, pixel bandwidth $=15.63 \mathrm{~Hz}$, frequency $=256 \mathrm{~Hz}$, phase $=256$, number of acquisitions $=3$, field of view $=60 \mathrm{~mm}$, phase field of view $=1$, slice thickness $=1.0 \mathrm{~mm}$, number of slices $=24$, and spacing gap $=1.1 \mathrm{~mm}$.

\section{Results}

\subsection{Particle Size, Colloidal Stability, and Crystal Structure}

The colloidally stable FA-PAA-coated $\mathrm{MnO}$ nanoparticles were prepared via a simple one-pot polyol method (last step in Figure 1). The nanoparticle diameter (d) was measured via HRTEM. The nanoparticles were ultrasmall (Figure 2a-i), and a magnified image of a 
nanoparticle, indicated as a dotted circle in Figure 2a-i, showed the MnO nanoparticle lattice fringes (Figure 2a-ii). The estimated average particle diameter was $2.7 \pm 0.1 \mathrm{~nm}$ from a lognormal function fit to the observed particle diameter distribution (Figure $2 \mathrm{~b}$ and Table 1 ). The hydrodynamic diameter (a) of the FA-PAA-coated MnO nanoparticles was measured via DLS, and the estimated average hydrodynamic diameter was $22.2 \pm 0.1 \mathrm{~nm}$ from a log-normal function fit to the observed hydrodynamic diameter distribution (Figure $2 \mathrm{c}$ and Table 1).
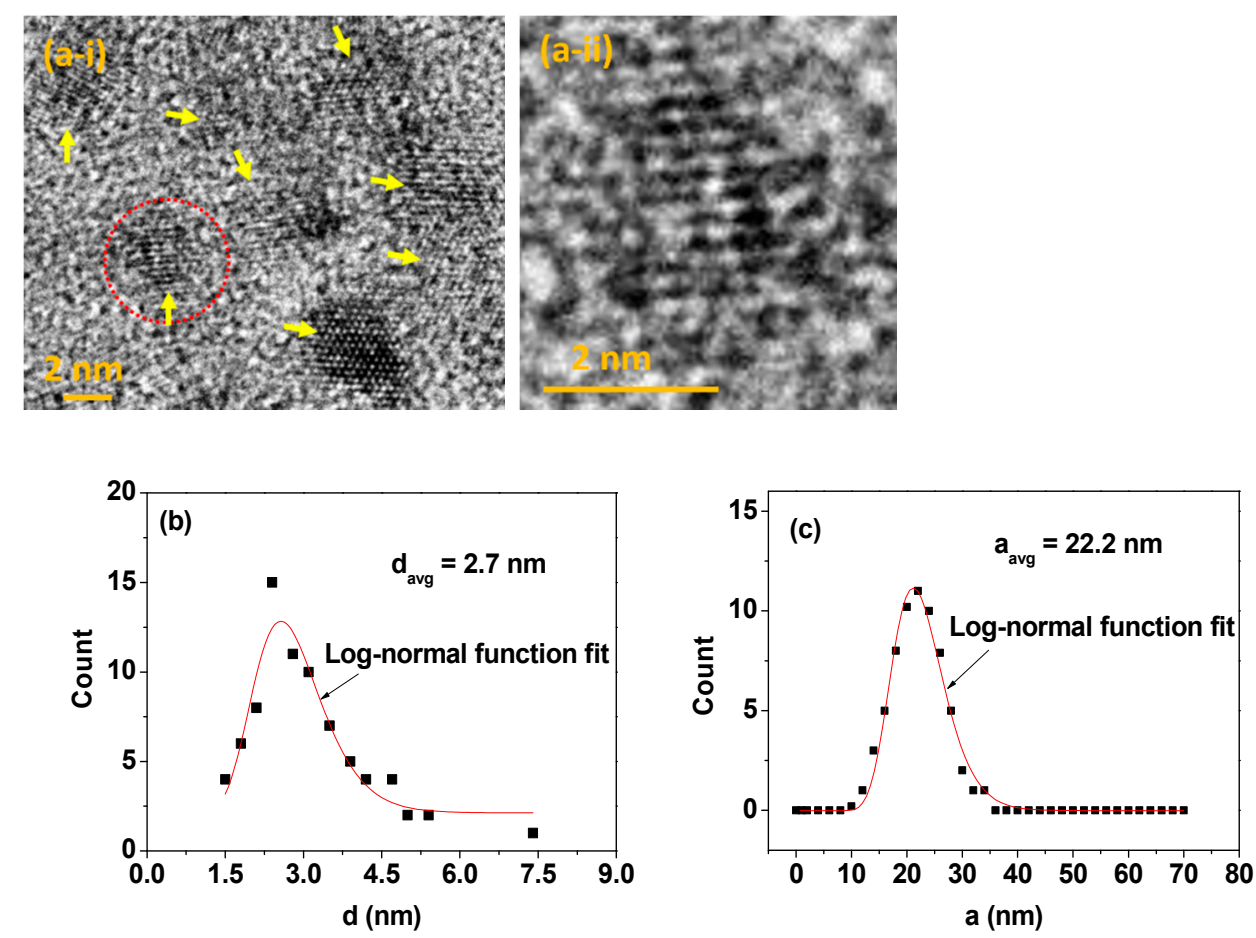

Figure 2. (a-i) High-resolution transmission electron microscope (HRTEM) image (arrows indicate FA-PAA-coated MnO nanoparticles) and (a-ii) a magnified image of a nanoparticle indicated as a dotted circle in (a-i). (b) Particle diameter distribution. (c) Hydrodynamic diameter distribution.

Table 1. Summarized properties of the FA-PAA-coated MnO nanoparticles.

\begin{tabular}{|c|c|c|c|c|c|c|c|c|c|c|}
\hline \multicolumn{3}{|c|}{$\begin{array}{l}\text { Particle Dimension } \\
\text { (nm) }\end{array}$} & \multicolumn{3}{|c|}{$\begin{array}{l}\text { Surface-Coating } \\
\text { Amount }\end{array}$} & \multicolumn{3}{|c|}{ Magnetic Properties } & \multicolumn{2}{|c|}{$\begin{array}{c}\text { Water Proton Spin } \\
\text { Relaxivity } \\
\left(\mathrm{s}^{-1} \mathrm{mM}^{-1}\right)\end{array}$} \\
\hline \multirow{2}{*}{$\mathrm{d}_{\mathrm{avg}}{ }^{1}$} & \multirow{2}{*}{$\mathrm{a}_{\mathrm{avg}}{ }^{2}$} & \multirow{2}{*}{$\begin{array}{c}\xi_{\text {avg }}^{3} \\
(\mathrm{mV})\end{array}$} & \multirow{2}{*}{$\underset{\left(w t^{\circ} \%\right)}{\mathrm{P}^{4}}$} & \multirow{2}{*}{$\begin{array}{c}\sigma^{5} \\
(1 / \mathrm{nm})\end{array}$} & \multirow{2}{*}{$\mathrm{N}^{6}$} & \multirow[t]{2}{*}{ Magnetism } & $\begin{array}{r}\text { Net mas } \\
\text { (en }\end{array}$ & $\begin{array}{l}\text { ization } \\
\text { g) }\end{array}$ & \multirow[t]{2}{*}{$\mathrm{r}_{1}$} & \multirow[t]{2}{*}{$r_{2}$} \\
\hline & & & & & & & $100 \mathrm{~K}$ & $300 \mathrm{~K}$ & & \\
\hline $2.7 \pm 0.1$ & $22.2 \pm 0.1$ & $-32.6 \pm 0.4$ & 44.6 & 0.6 & 14 & Paramagnetic & 3.2 & 1.1 & $9.3 \pm 0.1$ & $20.4 \pm 0.4$ \\
\hline
\end{tabular}

${ }^{1} \mathrm{~d}_{\text {avg}}$ : Average particle diameter. ${ }^{2} \mathrm{a}_{\text {avg }}$ : Average hydrodynamic diameter. ${ }^{3} \xi_{\text {avg: }}$ Average zeta potential. ${ }^{4}$ P: Average surface-coating amount per nanoparticle in $w t \% .{ }^{5} \sigma$ : Average grafting density. ${ }^{6} \mathrm{~N}$ : Average number of FA-PAA ligands coating a nanoparticle.

The nanoparticle colloidal stability was confirmed by visually inspecting the aqueous nanoparticle suspension sample (36.4 mM Mn) (Figure 3a-i): since preparation, no nanoparticle precipitation occurred ( $>1$ year). Further, no nanoparticle precipitation occurred for the dilute aqueous nanoparticle suspension samples $(2.0 \mathrm{mM} \mathrm{Mn})$ in the presence of $1.0 \mathrm{mM} \mathrm{Ca}^{2+}$ and $\mathrm{Mg}^{2+}$ ions for 5 days (Figure 3a-ii,a-iii, respectively, indicating no effects of these biologically important ions on the nanoparticle colloidal stability). Additionally, the high zeta potential ( $\xi$ ) of $-32.6 \pm 0.4 \mathrm{mV}$ (Figure $3 \mathrm{~b}$ and Table 1 ) further confirmed the colloidal stability. Colloidal dispersion was confirmed through the Tyndall effect: laser light scattering was only observed in the nanoparticle suspension sample, caused by the 
collision between the nanoparticle colloids and the passing laser light. Contrastingly, it was not observed in the reference triple-distilled water (Figure 3c).
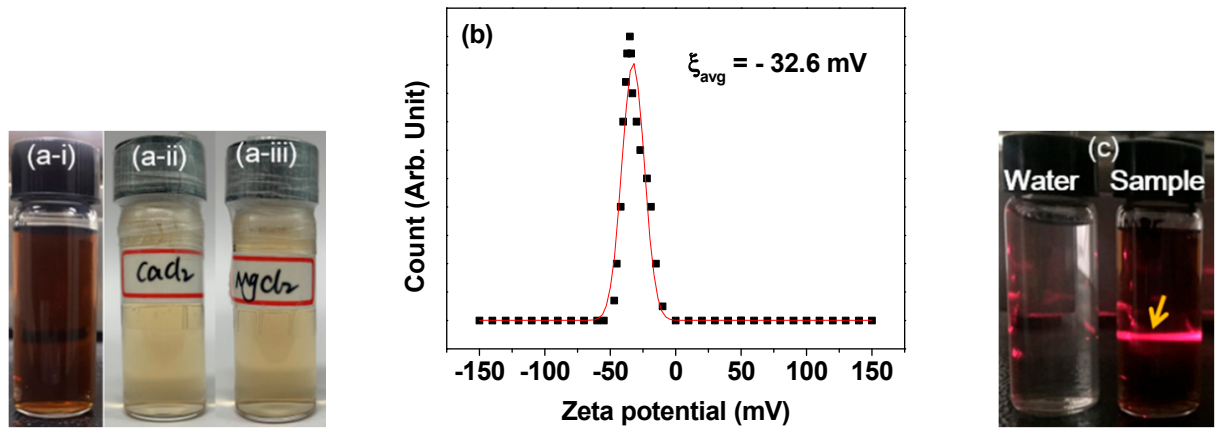

Figure 3. Photographs of (a-i) an aqueous nanoparticle dispersion sample (since preparation, no nanoparticle precipitation was observed for $>1$ year, proving the good nanoparticle colloidal stability) and those of dilute aqueous nanoparticle dispersion samples in the presence of $1.0 \mathrm{mM}$ (a-ii) $\mathrm{Ca}^{2+}$ and (a-iii) $\mathrm{Mg}^{2+}$ ions (no nanoparticle precipitation occurred for 5 days, indicating no effects of these ions on the nanoparticle colloidal stability). (b) Zeta potential curve. (c) Tyndall effect showing laser light scattering through a laser path (labeled with an arrow) for the aqueous nanoparticle dispersion sample (right vial), whereas no such effect was observed in the triple-distilled water (left vial), confirming the colloidal dispersion.

As shown in Figure 4, the XRD pattern obtained before TGA show significantly broad peaks (bottom spectrum), probably since most of the nanoparticles were not fully crystallized owing to their ultrasmall particle sizes. However, after TGA, sharp peaks were observed (top spectrum), due to the particle growth and crystallization of the nanoparticles. All post-TGA peaks could be assigned with (hkl) Miller indices. They corresponded to the cubic structure of $\mathrm{MnO}$ with characteristic peaks of (111), (200), (220), (311), (222), and (400) as indicated on the top of the XRD pattern. The estimated cell constant (L) of $4.43 \pm 0.1 \AA$ was consistent with the reported value [30].

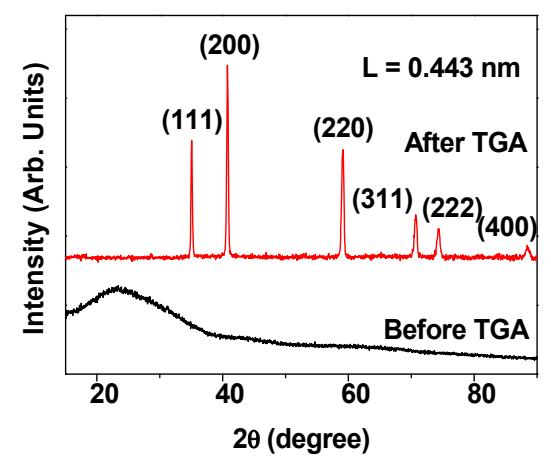

Figure 4. XRD patterns before and after thermogravimetric analysis (TGA). The post-TGA peaks were assigned with (hkl) Miller indices. "L": cell constant of MnO.

\subsection{Surface-Coating}

The FA-PAA coating on the nanoparticles was confirmed from the FT-IR absorption spectrum of the FA-PAA-coated MnO nanoparticles (bottom spectrum in Figure 5a). The FT-IR absorption spectra of FA, PAA, and FA-PAA were also recorded for reference (top three spectra in Figure 5a). The C-H symmetric stretching peak at $2940 \mathrm{~cm}^{-1}$ was observed in all FT-IR absorption spectra, supporting that the $\mathrm{MnO}$ nanoparticles were coated with FA-PAA. The $\mathrm{C}=\mathrm{C}$ aromatic ring symmetric stretching peak at $1602 \mathrm{~cm}^{-1}$ in the spectrum of FA also appeared in the spectrum of FA-PAA, confirming the successful conjugation of FA with PAA through an amide bond between the $-\mathrm{NH}_{2}$ group of FA and the $-\mathrm{COOH}$ group of PAA. This peak also appeared in the spectrum of the FA-PAA-coated MnO 
nanoparticles, confirming that the $\mathrm{MnO}$ nanoparticles were coated with FA-PAA. The $\mathrm{C}=\mathrm{O}$ symmetric stretching peak at $1688 \mathrm{~cm}^{-1}$ in the FA-PAA spectrum was split into $\mathrm{COO}^{-}$ antisymmetric stretching at $1540 \mathrm{~cm}^{-1}$ and $\mathrm{COO}^{-}$symmetric stretching at $1396 \mathrm{~cm}^{-1}$ in the spectrum of FA-PAA-coated MnO nanoparticles, which were red-shifted by 148 and $292 \mathrm{~cm}^{-1}$, respectively. This is owing to the strong coordination bonding between the $-\mathrm{COO}^{-}$group of PAA of FA-PAA and the $\mathrm{Mn}^{2+}$ species on the nanoparticle surface. Such splittings and red-shifts have been observed previously in various ligands with carboxylic groups bonded to metal oxides [31,32], which support our results.
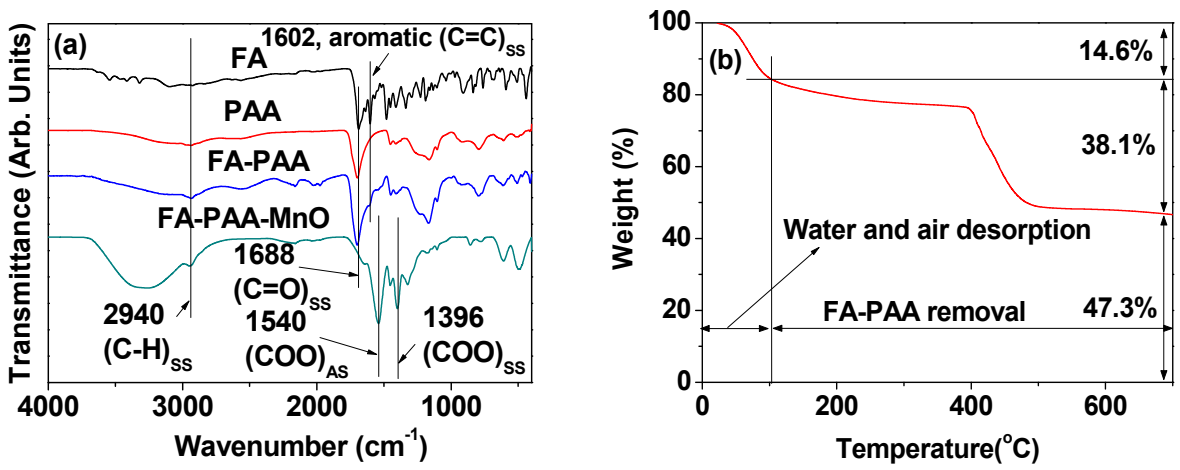

Figure 5. (a) FT-IR absorption spectra of the FA-PAA-coated MnO nanoparticles, FA, PAA, and FA-PAA. The subscripts, "AS": Antisymmetric stretch and "SS": Asymmetric stretch. (b) TGA curve.

The average surface-coating amount of FA-PAA was estimated from the TGA curve (Figure 5b). After heating the powder sample from room temperature to $700{ }^{\circ} \mathrm{C}$, a decrease in mass was observed in the TGA curve. The initial decrease in mass $(14.6 \mathrm{wt} \%)$ between the room temperature and $\sim 100{ }^{\circ} \mathrm{C}$ was owing to air and water desorption, whereas the following mass decrease $(\mathrm{P})(38.1 \mathrm{wt} \%)$ was due to the FA-PAA removal from the nanoparticles by flowing hot nitrogen. The remaining mass $(47.3 \mathrm{wt} \%)$ was attributed to the $\mathrm{MnO}$ nanoparticles, as confirmed from the XRD pattern obtained after TGA (Figure 4). Therefore, $44.6 \mathrm{wt} \%$ FA-PAA [obtained as 38.1/(1 - 0.146)] is estimated to be in the FA-PAA-coated MnO nanoparticles. The average number of FA-PAA molecules grafted per nanoparticle unit surface area, i.e., the grafting density $(\sigma)$ [33], was estimated to be $0.6 \mathrm{~nm}^{-1}$ using the above-mentioned P-value of FA-PAA, the $\mathrm{d}_{\text {avg }}$ estimated via HRTEM imaging, and the bulk density of $\mathrm{MnO}\left(5.45 \mathrm{~g} / \mathrm{cm}^{3}\right)$ [34]. The average number $(\mathrm{N})$ of FA-PAA molecules coating a nanoparticle surface was determined as the product of $\sigma$ by the nanoparticle surface area $\left(\pi \mathrm{d}_{\mathrm{avg}}{ }^{2}\right)$, which was found to be $\sim 14$. Table 1 summarized the surface-coating results.

\subsection{Magnetic Properties}

The mass-corrected $\mathrm{M}-\mathrm{H}$ curves of the powder sample at $\mathrm{T}=100$ and $300 \mathrm{~K}$ are presented in Figure 6 . The $\mathrm{M}-\mathrm{H}$ curve at $\mathrm{T}=100 \mathrm{~K}$ was slightly noisy due to a slight instability in the temperature control of the instrument at low temperature. However, it was stable at room temperature (i.e., $\mathrm{T}=300 \mathrm{~K}$ ). The $\mathrm{M}-\mathrm{H}$ curves showed the lack of saturation magnetization and a zero value in both remanence and coercivity, i.e., no hysteresis. This lack of saturation magnetization and hysteresis indicates that the $\mathrm{MnO}$ nanoparticles are paramagnetic, as observed previously [35]. From the mass-corrected $\mathrm{M}-\mathrm{H}$ curves, the net $\mathrm{M}$ values of the $\mathrm{MnO}$ nanoparticles at $\mathrm{T}=100$ and $300 \mathrm{~K}$ at $\mathrm{H}=2.0 \mathrm{~T}$ were estimated to be 3.2 and $1.1 \mathrm{emu} / \mathrm{g}$, respectively (Table 1). Since the bulk MnO is antiferromagnetic, the observed appreciable $M$ values of the nanoparticles are mainly attributable to the many unpaired paramagnetic 3 d-electron spins $(S=5 / 2)$ of $\mathrm{Mn}^{2+}$ species on the nanoparticle surfaces since the observed particle diameters were ultrasmall $[13,14]$. 


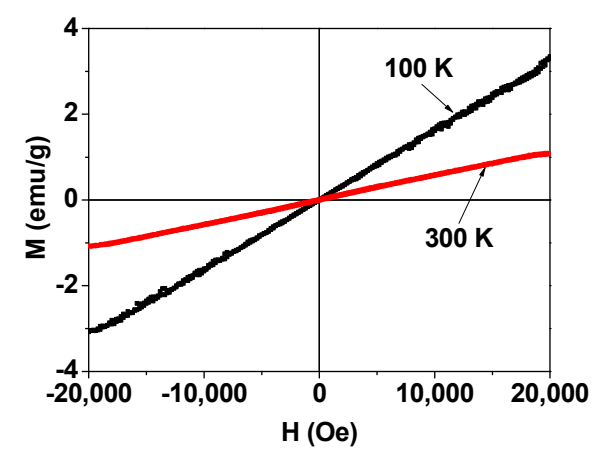

Figure 6. Mass-corrected magnetization versus the applied field (i.e., $\mathrm{M}-\mathrm{H})$ curves $(-2.0 \mathrm{~T} \leq \mathrm{H} \leq 2.0 \mathrm{~T})$ at $\mathrm{T}-100$ and $300 \mathrm{~K}$. The $\mathrm{M}$ values are the net $\mathrm{M}$ values of the $\mathrm{MnO}$ nanoparticles without FA-PAA (see text for details). The $\mathrm{M}-\mathrm{H}$ curve at $\mathrm{T}=100 \mathrm{~K}$ was slightly noisy owing to the slight temperature instability of the instrument.

\subsection{In Vitro Cell Viabilities}

No significant loss in cell viabilities up to $200 \mu \mathrm{M}$ Mn was observed for the FA-PAAcoated MnO nanoparticles in the DU145 and NCTC1469 cells (Figure 7), indicating the suitability of the nanoparticles for in vivo applications.

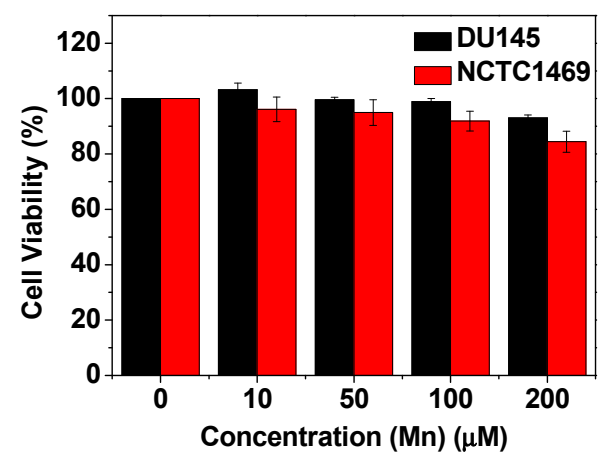

Figure 7. Cell viabilities of NCTC1469 and DU145 cells for the FA-PAA-coated MnO nanoparticles, exhibiting very low toxicities of up to $200 \mu \mathrm{M}$ Mn.

\subsection{Water Proton Spin Relaxivity Values}

The $r_{1}$ and $r_{2}$ relaxivities of the FA-PAA-coated $\mathrm{MnO}$ nanoparticles, i.e., the slopes of the $1 / T_{1}$ and $1 / T_{2}$ plots versus the Mn-concentration, respectively, were estimated to investigate their potential as an MRI contrast agent. As shown in Figure 8a and Table 1, the estimated $r_{1}$ and $r_{2}$ values were $9.3 \pm 0.1$ and $20.4 \pm 0.4 \mathrm{mM}^{-1} \mathrm{~s}^{-1}\left(\mathrm{r}_{2} / \mathrm{r}_{1}=2.2\right)$, respectively. In addition, dose-dependent contrast enhancements were clearly observed in the longitudinal $\left(R_{1}\right)$ and transverse $\left(R_{2}\right)$ map images (Figure $8 b$ ), evidencing that the FAPAA-coated MnO nanoparticles can act as both $\mathrm{T}_{1}$ and $\mathrm{T}_{2}$ MRI contrast agents. However, the $r_{1}$ value was high and the $r_{2} / r_{1}$ ratio was somewhat close to one, corresponding to highly suitable conditions for successful application as a $T_{1}$ MRI contrast agent $[7,8]$. Thus, the FA-PAA-coated $\mathrm{MnO}$ nanoparticles were applied as a $\mathrm{T}_{1}$ MRI contrast agent in this study. 

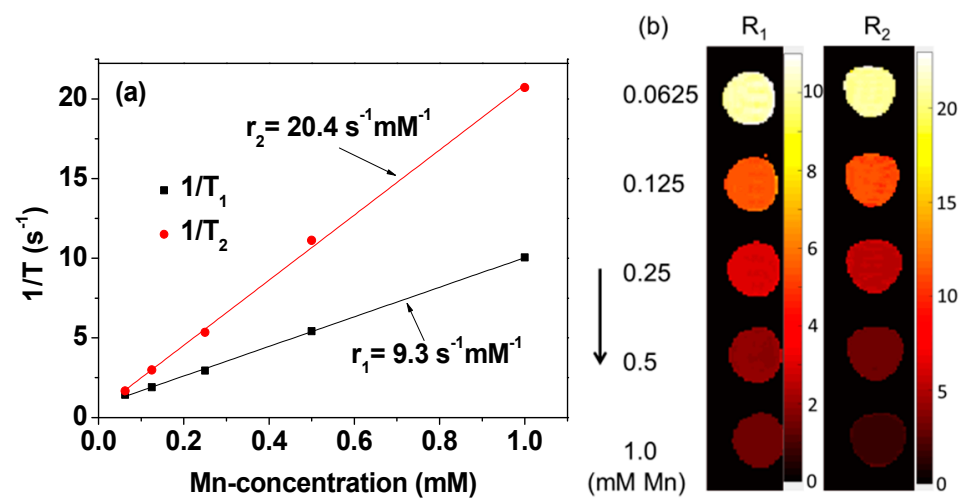

Figure 8. (a) $1 / \mathrm{T}_{1}$ and $1 / \mathrm{T}_{2}$ plots versus the Mn-concentration. The $\mathrm{r}_{1}$ and $\mathrm{r}_{2}$ values were estimated from the corresponding slopes, respectively. (b) Dose-dependent contrast enhancements in $R_{1}$ and $\mathrm{R}_{2}$ map images.

\subsection{In Vivo $T_{1} M R I$}

The nanoparticle suspension sample was intravenously administrated to the tails of the brain cancer model nude mice. The $\mathrm{T}_{1} \mathrm{MR}$ images were taken before and after the administration. As shown in Figure 9a, positive contrast enhancements were clearly observed at the brain cancer site after administration. To quantitatively evaluate the contrast enhancements, the signal-to-noise ratio (SNR) of a region of interest (ROI) (denoted as red dots indicated with arrows) at both the cancer and normal brain tissues was plotted versus time (Figure 9b). The contrast enhancements at the brain cancer site were stronger than those at the normal brain tissue, indicating the high accumulation of nanoparticles at the brain cancer site. In addition, the [\{contrast $(24 \mathrm{~h})-$ contrast $(0 \mathrm{~h})\}$ / contrast $(0 \mathrm{~h})]$ value at the brain cancer site was approximately seven times higher than that at the normal brain tissue, indicating the prolonged retention of the nanoparticles at the cancer site, which is likely attributable to the cancer-targeting function of the nanoparticles.
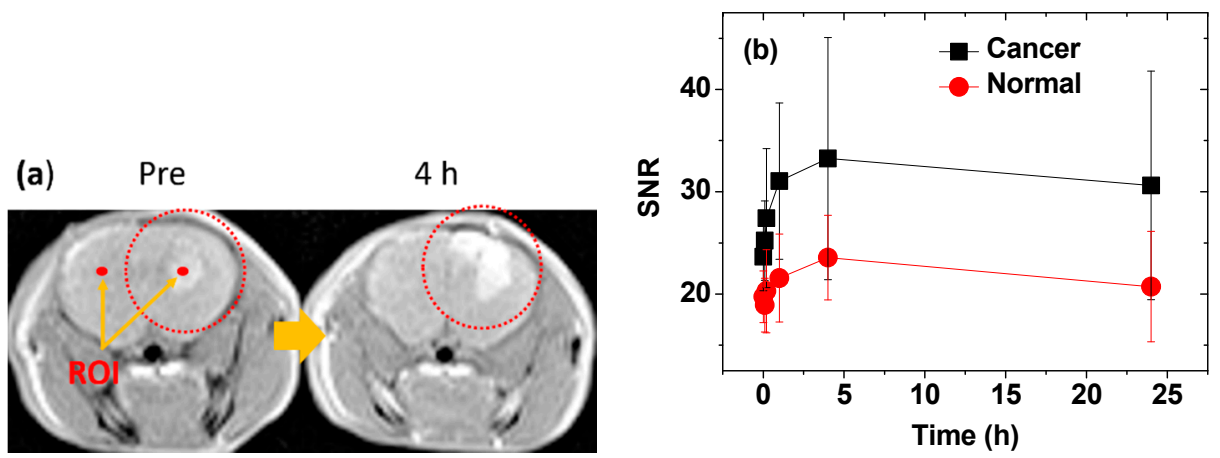

Figure 9. (a) $\mathrm{T}_{1}$ magnetic resonance (MR) images before (pre $=0 \mathrm{~h}$ ) and $4 \mathrm{~h}$ after intravenous administration. The dotted circles indicate the location of the brain cancer. Region-of-interest (ROI) at the brain cancer site and normal brain tissue (labeled with small dots and arrows). (b) Plots of SNR-ROI versus time, where SNR is the signal-to-noise ratio.

\section{Discussion}

Both the colloidal stability and the biocompatibility of the nanoparticles are essential for their in vivo biomedical applications. The FA-PAA-coated $\mathrm{MnO}$ nanoparticles exhibited these properties owing to the hydrophilic and biocompatible PAA polymers grafted on their surfaces.

The observed high $r_{1}$ value and the $r_{2} / r_{1}$ ratio which was somewhat close to one are attributable to the strong interactions between the many $\mathrm{Mn}^{2+}$ species on the nanoparticle surfaces and the numerous water molecules around the nanoparticles attracted by PAA (Figure 10a), as confirmed by the large hydrodynamic diameter of the nanoparticles. 
This type of interaction corresponds to the magnetic dipole-dipole interaction between $3 \mathrm{~d}$-electron spins $(\mathrm{S}=5 / 2)$ of $\mathrm{Mn}^{2+}$ and water proton spins $(\mathrm{s}=1 / 2)$ [8]. As shown in Figure 10b, the longitudinal water proton spin relaxation from the $\beta$-spin $(-1 / 2)$ to the $\alpha$-spin $(1 / 2)$ is strongly stimulated by the $3 \mathrm{~d}$-electron spins of $\mathrm{Mn}^{2+}$ since slow electron spin motions match well with the proton spin relaxations $[7,8]$. Under such conditions, the $\mathrm{T}_{1}$ relaxation times of the water proton spins significantly decrease, resulting in a high $r_{1}$ value, as observed in various hydrophilic polymer-coated gadolinium oxide nanoparticles [36-38].

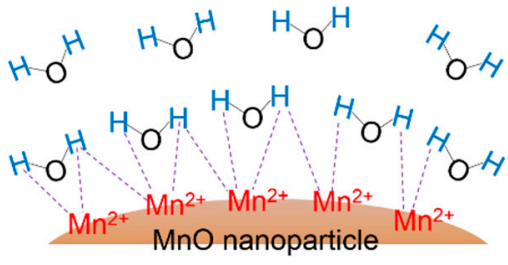

(a)

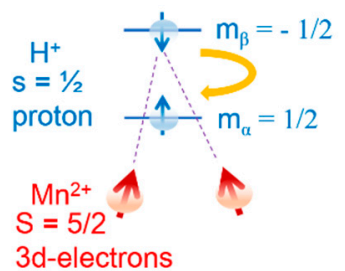

(b)

Figure 10. (a) Magnetic dipole-dipole interactions between the $\mathrm{Mn}^{2+}(\mathrm{S}=5 / 2)$ species on the $\mathrm{MnO}$ nanoparticle surface and the water proton spins $(s=1 / 2)$, as indicated by the dotted lines. The FA-PAA ligands coating the nanoparticle surface were omitted for simplicity. (b) Stimulation of the longitudinal water proton spin relaxation from the $\beta$-spin $\left(m_{\beta}=-1 / 2\right)$ to $\alpha$-spin $(m=1 / 2)$ by the 3d-electron spins $(\mathrm{S}=5 / 2)$ of $\mathrm{Mn}^{2+}$ (here, two stimulating $\mathrm{Mn}^{2+}$ species are arbitrarily shown).

As a comparison, the $\mathrm{r}_{1}$ values of various $\mathrm{MnO}$ nanoparticles and metal-ion chelates are provided in Table 2. As presented in Table 2, the $\mathrm{r}_{1}$ values of large $\mathrm{MnO}$ nanoparticles $\left(\mathrm{d}_{\mathrm{avg}}>10 \mathrm{~nm}\right)$ [20,39-41] are smaller than those [35] of ultrasmall MnO nanoparticles $\left(\mathrm{d}_{\mathrm{avg}}<3 \mathrm{~nm}\right)$, including that in this study. This is due to the fact that ultrasmall nanoparticles possess higher surface-to-volume ratios than large nanoparticles, and thus, they possess a higher number of surface $\mathrm{Mn}^{2+}$ with $S=5 / 2$ per nanoparticle that interact with water proton spins $(s=1 / 2)$ (Figure 10a,b). In addition, the $r_{1}$ value of the FA-PAA-coated $\mathrm{MnO}$ nanoparticles is 2-3 times higher than those [7,8] of the molecular $\mathrm{Gd}^{3+}$ - and $\mathrm{Mn}^{2+}$. chelates (Table 2). This property corresponds to the advantage of ultrasmall nanoparticle contrast agents over molecular contrast agents, which likely results from the high density of the $\mathrm{Mn}^{2+}$ species on the nanoparticle surface that can interact with many water molecules (Figure 10a), whereas only a few water molecules are allowed to interact with the central $\mathrm{Gd}^{3+}$ or $\mathrm{Mn}^{2+}$ ion in molecular contrast agents [6-8].

Table 2. Comparison of the $\mathrm{r}_{1}$ values of various $\mathrm{MnO}$ nanoparticles and metal-ion chelates.

\begin{tabular}{|c|c|c|c|c|c|}
\hline Core & Coating Ligand or Chelate & $\begin{array}{l}d_{\text {avg }} \\
(\mathrm{nm})\end{array}$ & $\begin{array}{c}\mathrm{r}_{1} \\
\left(\mathrm{~s}^{-1} \mathrm{mM}^{-1}\right)\end{array}$ & $\begin{array}{l}\text { Applied Field } \\
\text { (T) }\end{array}$ & Ref. \\
\hline MnO nanoparticle & PEG $^{1}$-phospholipid & 20 & 0.21 & 3.0 & [39] \\
\hline MnO nanoparticle & Mesoporous $\mathrm{SiO}_{2}$ & 15 & 0.65 & 11.7 & [40] \\
\hline MnO nanoparticle & Human serum albumin & 25.2 & 1.97 & 7.0 & [41] \\
\hline MnO nanoparticle & FA-TETT $^{2}$ & 16.8 & 4.83 & 7.0 & [20] \\
\hline MnO nanoparticle & D-glucuronic acid & 2.5 & 7.02 & 1.5 & [35] \\
\hline MnO nanoparticle & FA-PAA ${ }^{3}$ & 2.7 & 9.3 & 3.0 & This study \\
\hline $\mathrm{Mn}^{2+}$ ion & EDTA $^{4}$ & - & 2.9 & 0.47 & [8] \\
\hline $\mathrm{Gd}^{3+}$ ion & DTPA $^{5}$ & - & 4.1 & 0.47 & [8] \\
\hline
\end{tabular}

${ }^{1}$ PEG: Poly(ethylene glycol). ${ }^{2}$ FA-TETT: Folic acid conjugated N-(trimethoxysilylpropyl) ethylene diamine triacetic acid. ${ }^{3}$ FA-PAA: Folic acid conjugated polyacrylic acid. ${ }^{4}$ EDTA: Ethylenediaminetetraacetic acid. ${ }^{5}$ DTPA: Diethylenetriaminepentaacetic acid.

Herein, the FA-PAA-coated MnO nanoparticles exhibited stronger positive contrast enhancements at the brain cancer site compared to those at the normal brain tissue. This is due to the fact that FA possesses a high binding affinity towards folate receptors, which are over-expressed on U87MG cancer cells [42]. This result demonstrates the application potential of FA-PAA-coated MnO nanoparticles as a cancer-targeting $\mathrm{T}_{1}$ MRI contrast agent. 


\section{Conclusions}

FA-PAA-coated $\mathrm{MnO}$ nanoparticles with ultrasmall particle diameters $\left(\mathrm{d}_{\mathrm{avg}}=2.7 \mathrm{~nm}\right)$ were prepared through a simple one-pot polyol method in this study. The results are summarized as follows:

(1) The PAA coating conferred good colloidal stability and low cellular cytotoxicity, while FA conferred cancer-targeting ability on the nanoparticles.

(2) The FA-PAA-coated MnO nanoparticles exhibited a high value of $\mathrm{r}_{1}=9.3 \mathrm{~s}^{-1} \mathrm{mM}^{-1}$ $\left(\mathrm{r}_{2} / \mathrm{r}_{1}=2.2\right)$ owing to the strong interactions between the numerous $\mathrm{Mn}^{2+}$ species on the nanoparticle surfaces and the many water molecules around the nanoparticles attracted by PAA.

(3) The effectiveness of the FA-PAA-coated $\mathrm{MnO}$ nanoparticles as a cancer-targeting $\mathrm{T}_{1}$ MRI contrast agent was proved by the strong positive contrast enhancements of the brain cancer site compared to those of the normal brain tissue.

Author Contributions: Methodology, S.M. and S.-L.H.; conceptualization, S.M.; formal analysis, S.M., H.Y., S.L., T.T., M.Y.A., A.K.A.A.S., D.Z. and Y.L.; investigation, S.M., H.Y., J.-A.P., S.K., J.-U.Y., H.C. and K.-S.C.; data curation, S.M., H.Y., J.-A.P., S.K., J.-U.Y., H.C. and K.-S.C.; writing-original draft preparation, S.M.; writing-review and editing, G.-H.L.; supervision, G.-H.L. and Y.C.; funding acquisition, G.-H.L. and Y.C. All authors have read and agreed to the published version of the manuscript.

Funding: This study was supported by the Basic Science Research Program (grant number 2016R1D1A3B01007622 to G.-H.L. and 2020R1A2C2008060 to Y.C.) of the National Research Foundation funded by the Ministry of Education, Science, and Technology.

Institutional Review Board Statement: The in vivo animal imaging experiments were performed according to the rules and regulation of the animal research committee of the Korea Institute of Radiological and Medical Sciences (approval number: Kirams2018-0072 and approval data: 9 January 2019).

Informed Consent Statement: Not applicable.

Data Availability Statement: The data presented in this study are available on request from the corresponding authors.

Acknowledgments: We thank the Korea Basic Science Institute for allowing us to use their XRD machine.

Conflicts of Interest: The authors declare no conflict of interest.

\section{References}

1. Siegel, R.L.; Miller, K.D.; Jemal, A. Cancer statistics. CA Cancer J. Clin. 2020, 70, 7-30. [CrossRef]

2. Haris, M.; Yadav, S.K.; Rizwan, A.; Singh, A.; Wang, E.; Hariharan, H.; Reddy, R.; Marincola, F.M. Molecular magnetic resonance imaging in cancer. J. Transl. Med. 2015, 13, 313. [CrossRef] [PubMed]

3. Harisinghani, M.G.; O'Shea, A.; Weissleder, R. Advances in clinical MRI technology. Sci. Transl. Med. 2019, 18 , eaba2591. [CrossRef] [PubMed]

4. Xiao, Y.-D.; Paudel, R.; Liu, J.; Ma, C.; Zhang, Z.-S.; Zhou, S.-K. MRI contrast agents: Classification and application (Review). Int. J. Mol. Med. 2016, 38, 1319-1326. [CrossRef]

5. Na, H.B.; Song, I.C.; Hyeon, T. Inorganic nanoparticles for MRI contrast agents. Adv. Mater. 2009, 21, 2133-2148. [CrossRef]

6. Caravan, P. Strategies for increasing the sensitivity of gadolinium-based MRI contrast agents. Chem. Soc. Rev. 2006, 35, 512-523. [CrossRef]

7. Caravan, P.; Ellison, J.J.; McMurry, T.J.; Lauffer, R.B. Gadolinium(III) chelates as MRI contrast agents: Structure, dynamics, and applications. Chem. Rev. 1999, 99, 2293-2352. [CrossRef]

8. Lauffer, R.B. Paramagnetic metal complexes as water proton relaxation agents for NMR imaging: Theory and design. Chem. Rev. 1987, 87, 901-927. [CrossRef]

9. Wang, J.; Huang, Y.; David, A.E.; Chertok, B.; Zhang, L.; Yu, F.; Yang, V.C. Magnetic nanoparticles for MRI of brain tumors. Curr. Pharm. Biotechnol. 2012, 13, 2403-2416. [CrossRef] [PubMed]

10. Park, J.Y.; Baek, M.J.; Choi, E.S.; Woo, S.; Kim, J.H.; Kim, T.J.; Jung, J.C.; Chae, K.S.; Chang, Y.; Lee, G.H. Paramagnetic ultrasmall gadolinium oxide nanoparticles as advanced $\mathrm{T}_{1}$ MRI contrast agent: Account for large longitudinal relaxivity, optimal particle diameter, and in vivo $\mathrm{T}_{1}$ MR images. ACS Nano 2009, 3, 3663-3669. [CrossRef] [PubMed]

11. Pan, D.; Schmieder, A.H.; Wickline, S.A.; Lanza, G.M. Manganese-based MRI contrast agents: Past, present, and future. Tetrahedron 2011, 67, 8431-8444. [CrossRef] [PubMed] 
12. Zhen, Z.; Xie, J. Development of manganese-based nanoparticles as contrast probes for magnetic resonance imaging. Theranostics 2012, 2, 45-54. [CrossRef] [PubMed]

13. Sako, S.; Umemura, Y.; Ohshima, K.; Sakai, M.; Bandow, S. Magnetic property of antiferromagnetic MnO ultrafine-particle. J. Phys. Soc. Jpn. 1996, 65, 280-284. [CrossRef]

14. Trohidou, K.N.; Zianni, X.; Blackman, J.A. Surface effects on the magnetic behaviour of antiferromagnetic particles. J. Appl. Phys. 1998, 84, 2795-2800. [CrossRef]

15. Silva, A.C.; Lee, J.H.; Aoki, I.; Koretsky, A.P. Manganese-enhanced magnetic resonance imaging (MEMRI): Methodological and practical considerations. NMR Biomed. 2004, 17, 532-543. [CrossRef] [PubMed]

16. Reddy, J.A.; Allagadda, V.M.; Leamon, C.P. Targeting therapeutic and imaging agents to folate receptor positive tumors. Curr. Pharm. Biotechnol. 2005, 6, 131-150. [CrossRef]

17. Zhao, X.; Li, H.; Lee, R.J. Targeted drug delivery via folate receptors. Expert Opin. Drug Deliv. 2008, 5, 309-319. [CrossRef]

18. Leamon, C.P.; Reddy, J.A. Folate-targeted chemotherapy. Adv. Drug Deliv. Rev. 2004, 56, 1127-1141. [CrossRef]

19. Xia, W.; Low, P.S. Folate-targeted therapies for cancer. J. Med. Chem. 2010, 53, 6811-6824. [CrossRef] [PubMed]

20. Chen, N.; Shao, C.; Qu, Y.; Li, S.; Gu, W.; Zheng, T.; Ye, L.; Yu, C. Folic acid-conjugated MnO nanoparticles as a $\mathrm{T}_{1}$ contrast agent for magnetic resonance imaging of tiny brain gliomas. ACS Appl. Mater. Interfaces 2014, 6, 19850-19857. [CrossRef]

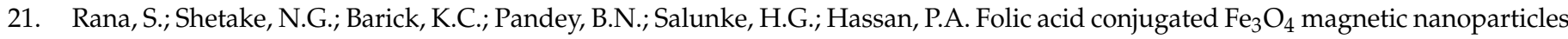
for targeted delivery of doxorubicin. Dalton Trans. 2016, 45, 17401-17408. [CrossRef]

22. Li, L.; Gao, F.; Jiang, W.; Wu, X.; Cai, Y.; Tangs, J.; Gao, X.; Gao, F. Folic acid-conjugated superparamagnetic iron oxide nanoparticles for tumor-targeting MR imaging. Drug Deliv. 2016, 23, 1726-1733. [CrossRef] [PubMed]

23. Chauhan, R.P.; Mathur, R.; Singh, G.; Kaul, A.; Bag, N.; Singh, S.; Kumar, H.; Patra, M.; Mishra, A.K. Evaluation of folate conjugated superparamagnetic iron oxide nanoparticles for scintigraphic/magnetic resonance imaging. J. Biomed. Nanotechnol. 2013, 9, 323-334. [CrossRef] [PubMed]

24. Quarta, A.; Curcio, A.; Kakwere, H.; Pellegrino, T. Polymer coated inorganic nanoparticles: Tailoring the nanocrystal surface for designing nanoprobes with biological implications. Nanoscale 2012, 4, 3319-3334. [CrossRef]

25. Larson, N.; Ghandehari, H. Polymeric conjugates for drug delivery. Chem. Mater. 2012, 24, 840-853. [CrossRef]

26. Lin, C.-L.; Lee, C.-F.; Chiu, W.-Y. Preparation and properties of poly(acrylic acid) oligomer stabilized superparamagnetic ferrofluid. J. Colloid Interface Sci. 2005, 291, 411-420. [CrossRef]

27. Sanchez, L.M.; Martin, D.A.; Alvarez, V.A.; Gonzalez, J.S. Polyacrylic acid-coated iron oxide magnetic nanoparticles: The polymer molecular weight influence. Colloid Surf. A 2018, 543, 28-37. [CrossRef]

28. Liufu, S.; Xiao, H.; Li, Y. Adsorption of poly(acrylic acid) onto the surface of titanium dioxide and the colloidal stability of aqueous suspension. J. Colloid Interface Sci. 2005, 281, 155-163. [CrossRef] [PubMed]

29. Henoumont, C.; Laurent, S.; Elst, L.V. How to perform accurate and reliable measurements of longitudinal and transverse relaxation times of MRI contrast media in aqueous solutions. Contrast Media Mol. Imaging 2009, 4, 312-321. [CrossRef]

30. Moore, T.E.; Ellis, M.; Selwood, P.W. Solid oxides and hydroxides of manganese. J. Am. Chem. Soc. 1950, 72, 856-866. [CrossRef]

31. Mendive, C.B.; Bredow, T.; Blesa, M.A.; Bahnemann, D.W. ATR-FTIR measurements and quantum chemical calculations concerning the adsorption and photoreaction of oxalic acid on $\mathrm{TiO}_{2}$. Phys. Chem. Chem. Phys. 2006, 8, 3232-3247. [CrossRef]

32. Daecon, G.B.; Philips, R.J. Relationships between the carbon-oxygen stretching frequencies of carboxylato complexes and the type of carboxylate coordination. Coord. Chem. Rev. 1980, 33, 227-250. [CrossRef]

33. Benoit, D.N.; Zhu, H.; Lilierose, M.H.; Verm, R.A.; Ali, N.; Morrison, A.N.; Fortner, J.D.; Avendano, C.; Colvin, V.L. Measuring the grafting density of nanoparticles in solution by analytical ultracentrifugation and total organic carbon analysis. Anal. Chem. 2012, 84, 9238-9245. [CrossRef]

34. Lide, D.R. CRC Handbook of Chemistry and Physics; Internet Version; CRC Press: Boca Raton, FL, USA, 2005 ; pp. 4-68.

35. Baek, M.J.; Park, J.Y.; Xu, W.; Kattel, K.; Kim, H.G.; Lee, E.J.; Patel, A.K.; Lee, J.J.; Chang, Y.; Kim, T.J.; et al. Water-soluble MnO nanocolloid for a molecular $T_{1}$ MR imaging: A facile one-pot synthesis, in vivo $T_{1}$ MR images, and account for relaxivities. ACS Appl. Mater. Interfaces 2010, 2, 2949-2955. [CrossRef] [PubMed]

36. Miao, X.; Ho, S.L.; Tegafaw, T.; Cha, H.; Chang, Y.; Oh, I.T.; Yaseen, A.M.; Marasini, S.; Ghazanfari, A.; Yue, H.; et al. Stable and non-toxic ultrasmall gadolinium oxide nanoparticle colloids (coating material = polyacrylic acid) as high-performance $\mathrm{T}_{1}$ magnetic resonance imaging contrast agents. RSC Adv. 2018, 8, 3189-3197. [CrossRef]

37. Jang, Y.-J.; Liu, S.; Yue, H.; Park, J.A.; Cha, H.; Ho, S.L.; Marasini, S.; Ghazanfari, A.; Ahmad, M.Y.; Miao, X.; et al. Hydrophilic biocompatible poly(acrylic acid-co-maleic acid) polymer as a surface-coating ligand of ultrasmall $\mathrm{Gd}_{2} \mathrm{O}_{3}$ nanoparticles to obtain a high $\mathrm{r}_{1}$ value and $\mathrm{T}_{1}$ MR images. Diagnostics 2021, 11, 2. [CrossRef]

38. Ahmad, M.Y.; Ahmad, M.W.; Yue, H.; Ho, S.L.; Park, J.A.; Jung, K.-H.; Cha, H.; Marasini, S.; Ghazanfari, A.; Liu, S.; et al. In vivo positive magnetic resonance imaging applications of poly(methyl vinyl ether-alt-maleic acid)-coated ultra-small paramagnetic gadolinium oxide nanoparticles. Molecules 2020, 25, 1159. [CrossRef] [PubMed]

39. Shin, J.; Anisur, R.M.; Ko, M.K.; Im, G.H.; Lee, J.H.; Lee, I.S. Hollow manganese oxide nanoparticles as multifunctional agents for magnetic resonance imaging and drug delivery. Angew. Chem. Int. Ed. 2009, 48, 321-324. [CrossRef]

40. Kim, T.; Momin, E.; Choi, J.; Yuan, K.; Zaidi, H.; Kim, J.; Park, M.; Lee, N.; McMahon, M.T.; Quinones-Hinojosa, A.; et al. Mesoporous silica-coated hollow manganese oxide nanoparticles as positive $\mathrm{T}_{1}$ contrast agents for labeling and MRI tracking of adipose derived mesenchymal stem cells. J. Am. Chem. Soc. 2011, 133, 2955-2961. [CrossRef] [PubMed] 
41. Huang, J.; Xie, J.; Chen, K.; Bu, L.; Lee, S.; Cheng, Z.; Li, X.; Chen, X. HSA coated MnO nanoparticles with prominent MRI contrast for tumor imaging. Chem. Commun. 2010, 46, 6684-6686. [CrossRef]

42. Marfavi, Z.H.; Farhadi, M.; Jameie, S.B.; Zahmatkeshan, M.; Pirhajati, V.; Jameie, M. Glioblastoma U-87MG tumour cells suppressed by ZnO folic acid-conjugated nanoparticles: An in vitro study. Artif. Cells Nanomed. Biotechnol. 2019, 47, $2783-2790$. [CrossRef] [PubMed] 